J. Biosoc. Sci., (2015) 47, 505-520, (C) Cambridge University Press, 2014. The online version of this article is published within an Open Access environment subject to the conditions of the Creative Commons Attribution-NonCommercial-ShareAlike licence <http://creativecommons.org/licenses/ by-nc-sa/3.0/>. The written permission of Cambridge University Press must be obtained for commercial re-use.

doi:10.1017/S002193201400011X First published online 16 Apr 2014

\title{
UNDERSTANDING LOW UPTAKE OF MASS TREATMENT FOR INTESTINAL SCHISTOSOMIASIS AMONG SCHOOL CHILDREN: A QUALITATIVE STUDY IN JINJA DISTRICT, UGANDA
}

\author{
SIMON MUHUMUZA*1, ANNETTE OLSEN $\uparrow$, FRED NUWAHA $†$ AND \\ ANNE KATAHOIRE*
}

* Child Health and Development Center, College of Health Sciences, Makerere University Kampala, Uganda, †Section for Parasitology and Aquatic Diseases, Faculty of Health and Medical Sciences, University of Copenhagen, Denmark and $\ddagger$ School of Public Health, Makerere University Kampala, Uganda

\begin{abstract}
Summary. Despite attempts to control intestinal schistosomiasis through schoolbased mass drug administration (MDA) with praziquantel using school teachers in Uganda, less than $30 \%$ of the school children take the treatment in some areas. The aim of the study was to understand why the uptake of praziquantel among school children is low and to suggest strategies for improved uptake. This was a cross-sectional qualitative study in which 24 focus group discussions and 15 key informant interviews were conducted 2 months after MDA. The focus group discussions were held with school children in twelve primary schools and the key informant interviews were held with school teachers, sub-county health assistants and the District Vector Control Officer. The study shows that the low uptake of praziquantel among school children is a result of a complex interplay between individual, interpersonal, institutional, community and public policy factors. The individual and interpersonal factors underpinning the low uptake include inadequate information about schistosomiasis prevention, beliefs and attitudes in the community about treatment of schistosomiasis and shared concerns among children and teachers about the side-effects of praziquantel, especially when the drug is taken on an empty stomach. The institutional, policy and community factors include inadequate preparation and facilitation of teachers and the school feeding policy, which requires parents to take responsibility for providing their children with food while at school, yet many parents cannot meet the cost of a daily meal due to the prevailing poverty in the area. It is concluded that strategies to improve uptake of praziquantel among school
\end{abstract}

\footnotetext{
${ }^{1}$ Corresponding author. Email: simonmhmz@yahoo.com
} 
children need to be multi-pronged addressing not only the preparation and motivation of teachers and health education for children, but also the economic and political aspects of drug distribution, including the school feeding policy.

\section{Introduction}

In Uganda, schistosomiasis is widespread along large lakes and rivers with approximately 4 million people infected and more than $13 \%$ of the population at risk of the infection (Kabatereine et al., 2004). In Jinja district, Schistosoma mansoni is highly endemic in areas along Lake Victoria, with $35 \%$ of the school-age children harbouring moderate infections of 116.1 eggs per gram (epg) of stool (Muhumuza et al., 2013b). The World Health Organization (WHO) recommends regular treatment programmes for schistosomiasis to target school-age children who could be reached through the primary school system (Engels et al., 2002). Since 2003, annual mass drug administration (MDA) using praziquantel has been implemented to reach children in primary schools located in areas endemic for schistosomiasis where all children are treated irrespective of their infection status (Kabatereine et al., 2006). It is hoped that since the drugs are distributed free of charge, children will become aware of the benefits of the treatment to their well-being and this, in turn, will generate a demand for them in the future (WHO, 2002, 2006).

Research undertaken in Uganda and Tanzania among adults has reported a reluctance to participate in MDA and the uptake of drugs for the treatment of schistosomiasis and other neglected tropical diseases has been low as a result (Parker et al., 2008, 2012; Parker \& Allen, 2011; Allen \& Parker, 2012). The uptake of praziquantel for schistosomiasis control has also been reported to be low among school children in Jinja district in Uganda, where it was estimated at 28.2\% during the 2011 MDA (Muhumuza et al., 2013b). Similarly, low levels of drug uptake among school children have been reported in Kenya (Miguel \& Kremer, 2002). The reasons why the uptake is low among school children are not clearly understood, although in common with Parker et al. (2008), it is likely that the economic and social context in which MDA is rolled out has influenced the low uptake of drugs. This article asks: why is the uptake of drugs so low among children? Can current strategies be re-designed to improve drug uptake?

This study drew on the socio-ecological model for health behaviour, which provides a useful framework for understanding the multiple factors that affect health behaviours and can be used to develop effective multi-level intervention strategies for improved health behaviour (Green et al., 1996; Richard et al., 1996; Stokols, 1996; Glanz et al., 2008). The multiple levels of influence often include intrapersonal, interpersonal, organizational, community and environmental factors (Glanz et al., 2008). According to the model, a health behaviour, such as uptake of preventive treatment for schistosomiasis, is thought to be influenced by an interwoven relationship between the individual and their environment, and that the most effective approach leading to the adoption of a health behaviour is a combination of individual-, interpersonal-, institutional- and communitylevel intervention strategies (McLeroy et al., 1988; Stokols, 1992; Painter et al., 2008). 


\section{Methods}

\section{Design}

A cross-sectional qualitative research design was adopted for this study. Two main data collection methods were used: focus group discussions and key informant interviews. The focus group discussions were held with school-going boys and girls aged 10-14 years in twelve primary schools and key informant interviews were held with school teachers, sub-county health assistants and the District Vector Control Officer.

\section{Study setting}

The study was conducted in Jinja district, south-eastern Uganda. Lake Victoria, which is the main source of $S$. Mansoni, forms the southern border of the district. The district has a population of more than 470,000 people, $79.1 \%$ of whom live in rural areas with a high population density of 686 per square kilometre. More than half $(56 \%)$ of the population in the district is below 18 years of age (UBOS, 2012). The majority of the population residing in the district are Basoga and speak the local language of Lusoga, which is similar to that spoken in the neighbouring districts of Iganga and Kamuli in the north and west, respectively, and in Mayuge in the east. Administratively, Jinja district is subdivided into seven rural sub-counties, one town council and three divisions in the municipality. The district has a total of 69 health facilities, 49 of which are public, seventeen are run by NGOs and three are institutional (army, police and prisons). There is $100 \%$ health facility coverage per parish with the majority of the population living within a $5 \mathrm{~km}$ radius of a health facility. The district has a health worker coverage of $73.2 \%$ in both public and private health facilities and is ranked among the top ten performing districts in terms of immunization coverage, antenatal care coverage, intermittent presumptive treatment with sulphadoxine/pyrimethamine (SP) for pregnant mothers, institutional deliveries and timeliness and completeness of health management information system reporting (MOH, 2010/2011).

The major causes of morbidity and mortality in the area include malaria, acute respiratory infections, HIV/AIDS, diarrhoeal diseases, schistosomiasis, soil-transmitted helminths, skin infections and complications of pregnancy and trauma. Schistosomiasis is endemic in the seven sub-counties of Walukuba, Mpumudde, Budondo, Butagaya, Kakira, Mafubira and Jinja Central. Schistosoma mansoni is the most predominant species in the district. The aquatic vegetation at the banks of Lake Victoria provides a good habitat for Biomphalaria snails, the intermediate hosts of S. mansoni. The communities that live within a $5 \mathrm{~km}$ radius of the lake are mostly affected. Subsistence farming, fishing and petty trade between the mainland and the islands are the main socioeconomic activities in the area. Lake Victoria is the main source of water for domestic use and agriculture. Family members including children constitute the single most important source of labour for agriculture and fishing. The mobility patterns of individuals and families living on the islands are usually seasonal, over long or short distances depending on the availability of fish, and this may partially explain the low uptake of treatment for schistosomiasis in the area. Serial cross-sectional studies conducted in the southern part of the district (Walukuba division) have shown a high prevalence of S. mansoni infection and low uptake of praziquantel treatment among school-age children (Muhumuza 
et al., 2009, 2013a, b). The studies further indicated that the majority of the children in the area fetch water, bathe, wash, fish and swim in the lake and are thus placed at risk of infection. The present study was conducted in primary schools in Walukuba division, Jinja municipality, Jinja district.

\section{Implementation of $M D A$ in primary schools}

In Jinja district, implementation of the schistosomiasis control programme started in August 2003. Mass drug administration is implemented as a stand-alone intervention in all primary schools in the seven sub-counties of the district where the infection is endemic. Mass treatment is provided in the primary schools on an annual basis. Prior to MDA, the Vector Control Division of the Ministry of Health conducts refresher training for members of the district health team and the district education office. The district then cascades training and supervision duties to the sub-county health assistants and inspector of schools who, in turn, train and supervise the school teachers. The training mainly focuses on registration of the children prior to MDA, drug distribution and recording of treatment in the treatment registers. In addition, awareness of schistosomiasis transmission and control (including taking preventive treatment) is communicated through radio talk shows, radio spot messages and the distribution of information, education and communication materials. The drugs, tally sheets and registers are distributed to the primary schools after the training. During MDA, a central location in each school is organized for drug administration. Children are invited to receive treatment according to their school grade. Praziquantel is distributed by the teachers who also record the treatment in the registers. The process of drug distribution in primary schools has been described previously (Muhumuza et al., 2013b). Since 2003, the MDA activities have been supported through a parallel structure within the Ministry of Health with external funding from the United States Agency for International Development (USAID) channelled through Research Triangle Institute (RTI) International. However, uptake of praziquantel among school children has remained low: 42\% in 2009 (Muhumuza et al., 2009), 28.2\% in 2011(Muhumuza et al., 2013b) and 48.9\% in 2012 (Muhumuza et al., 2013a).

\section{Data collection}

Focus group discussions and key informant interviews were conducted between July and August 2012, two months after the 2012 MDA. Twenty-four focus group discussions and fifteen key informant interviews were held during the study. Twelve of the key informants were school teachers in charge of health and sanitation, two were health assistants in charge of Walukuba and Central divisions in Jinja municipality and one was the District Vector Control Officer.

The focus group discussions involved pupils purposively selected from primary grades 4-6 who were 10-14 years, which is the peak age for schistosomiasis infection in Uganda (Kabatereine, 2004). The grade teachers assisted in the identification of children in this age group. Two focus group discussions (one for boys and one for girls), each comprising an average of 10-12 children, were conducted in each school. The focus group discussions with children explored their biomedical understanding of schistosomiasis, 
its transmission and prevention, and their experiences, attitudes and perceived barriers towards preventive chemotherapy with praziquantel. A discussion guide was used in guiding the discussions. Each focus group discussion had a moderator and a note taker. The moderator guided the discussions while the note taker tape-recorded and took additional notes to ensure a complete record of the discussions.

Key informants were purposively selected based on their knowledge and experience with the schistosomiasis control programme in the district. Interviews were conducted with school teachers in charge of health and sanitation, sub-county health assistants and the District Vector Control Officer. They have all been key players in the schistosomiasis control programme in the primary schools. A key informant interview guide was used in conducting the interviews. The guide explored the process of drug distribution, experiences and concerns about praziquantel treatment and suggestions for improved uptake. In both the focus group discussions and key informant interviews, data collection was an iterative process allowing for new questions to follow up on emerging issues. The important attributes defined at each level of the socio-ecological model shaped the topics and research questions. The individual and interpersonal attributes were explored through focus group discussions while the institutional and community attributes were explored through interviews.

\section{Data processing and analysis}

The tapes from focus group discussions were transcribed in the local language of Lusoga and subsequently translated into English. These were then organized according to the questions/topics explored in the guides. While reading through the various responses for particular questions, salient themes and recurring ideas with respect to the prevention of schistosomiasis, including experiences, attitudes and perceptions towards praziquantel treatment, were identified. The categorized data were then summarized by listing data that belonged together (Krueger, 1998). Analysis of the key informant interviews was based on the questions asked during the interviews. The interviews were organized according to the questions and the responses ordered accordingly. The responses were then grouped together and summarized. In both the focus group discussions and key informant interviews, a manual analysis sheet was used. The levels of influence of the socio-ecological model formed the basic units of analysis.

\section{Quality control}

Data collection was carried out by experienced research assistants who could speak the local language of Lusoga. They were trained in conducting focus group discussions and administering the individual key informant interviews and provided with background information about the MDA programme. Interview schedules were translated into Lusoga and then back into English to ensure consistence in meaning. All the focus group discussions were held in a quiet environment under the shade of a tree within the school premises. The key informant interviews were held in a quiet room. Data from focus group discussions and key informant interviews were triangulated for corroboration purposes. 


\section{Ethical considerations}

Ethical clearance for the study was obtained from Makerere University College of Health Sciences Higher Degrees, Research and Ethics Committee and the Uganda National Council for Science and Technology. Permission to conduct the study in the schools was obtained from the school management. Parents of the children were invited to the respective schools and informed about the study during a half-day meeting. Informed written consent was obtained from the parents after the meeting. The purpose and procedures of the study were also explained to the key informants prior to the interviews and were informed that their involvement was voluntary. Informed verbal consent was obtained from each key informant prior to the interview.

\section{Results}

\section{Individual and interpersonal factors}

The biomedical knowledge and understanding of schistosomiasis did not match the local understanding of the infection. The local term used to refer to schistosomiasis is ekidaada, which literally means a swollen stomach. It is locally perceived as an infection acquired from the lake. While children who participated in the focus group discussions were largely aware of ekidaada, their biomedical knowledge and understanding of its transmission and prevention was very limited indeed. Children were asked the different ways through which the disease can be acquired and prevented. Their responses reflected variations in knowledge of schistosomiasis transmission and control depending on the location of their schools and proximity to the lake. Children enrolled in schools located near the lake were more knowledgeable and were able to describe the different ways schistosomiasis is transmitted and how it can be prevented, as reflected in the following responses from a focus group discussion conducted in a school close to the lake:

Response 1: The disease is transmitted by swimming, defecating and urinating in the lake and the river.

Response 2: Bathing in dirty water is dangerous. If you step in the dirty water, you acquire this infection.

Response 3: Staying near water puts someone at risk of infection especially if you do not take treatment.

Response 4: Teachers advise us not to defecate in the lake to prevent transmitting the infection to other children. (Focus group discussion with boys aged 10-14 years, grades 4-6)

A few knew that there was medicine to prevent schistosomiasis, as illustrated by the following quote from one of the children:

There are tablets which make us healthy and prevent us from getting ekidaada although sometimes they have bad effects. (School boy, focus group discussion)

Another said:

We were told that there are tablets which kill the germs in the body ... we are supposed to swallow these drugs because they are for our benefit. (School boy, focus group discussion) 
The likely reasons for the higher levels of knowledge among the children in the schools located nearer the lake was explained by one health assistant who reported that the MDA programme often concentrated its health education efforts on the islands and places closer to the lake because these places have a higher prevalence of schistosomiasis. Less support for health education was provided in places further away from the lake. According to the health assistant:

Community leaders in areas around the lake, especially the islands, are facilitated with some small transport allowance to sensitize the communities. (Key informant, health assistant)

It was evident in the focus group discussions with children in schools located further away from the lake that their understanding of schistosomiasis transmission and prevention was limited, as illustrated by the following responses:

Response 1: Ekidaada can be prevented by drinking boiled water and eating food while it is still hot.

Response 2: Ekidaada can be prevented by washing hands before touching and eating any type of food.

Response 3: Ekidaada gets people who do not clean their compounds and eat uncooked vegetables.

Response 4: Cutting finger nails, drinking boiled water and getting immunization can prevent ekidaada. (Focus group discussion with girls aged 10-14 years, grades 4-6).

There was also minimal understanding of how schistosomiasis is transmitted. While some suggested that it could be acquired if they swam or bathed in the lake, others argued otherwise as illustrated by the following quote:

Most of us always swim, bathe and play in lake water. How come we do not have ekidaada? (School boy, focus group discussion)

While a number of children knew the drugs for treatment of schistosomiasis, they did not understand the rationale for preventive treatment, as illustrated by the questions they raised:

We know the drug that one can take to prevent ekidaada, but why should we take the drugs when we are not sick? (School girl, focus group discussion)

The inadequate understanding of schistosomiasis transmission and control was not only among children but was also prevalent among teachers. This was alluded to by one of the teachers in an interview:

Teachers are not sensitized enough; we are only trained how to administer the drug but we are not told what to communicate to the children. The science teachers are supposed to teach the children about schistosomiasis as part of the curriculum but they are not knowledgeable about the infection themselves. We do not know, for example, how these drugs work but we just dish them out. We don't know why some children react to the drugs and others do not. And when the children get side effects, we have nothing to do for them. (Key informant, teacher) 
These findings suggest that the inadequate knowledge of schistosomiasis transmission and control among school children could partly be explained by the physical location of their schools. Proximity to the lake partly determined the support provided by the MDA programme for health education in communities. The intensity and coverage of health education partly explained the variations in knowledge among the school children. Furthermore, while the MDA programme relied on school teachers to mobilize children for the preventive treatment, they expressed concern that they were inadequately prepared and did not receive any incentives for performing these tasks, which were not perceived as part of their regular duties. As a result, teachers do not prioritize MDA because they view it as outside of their official duties.

\section{Community and public policy factors}

Children's experiences with praziquantel treatment, and their attitudes and perceived barriers to treatment, were explored. Most of the children repeatedly described the discomfort experienced for several days after taking medication. They also expressed concern regarding the taste, smell and size of the tablets, as illustrated by the following quotes:

Response 1: The drugs are bitter and too big to swallow.

Response 2: The drugs smell very badly. (Focus group discussion with boys aged 10-14 years, grades 4-6)

A thread of concern that cut across all focus group discussions was the fear of sideeffects of praziquantel. Abdominal pain, diarrhoea, vomiting and dizziness were the most commonly reported side-effects, as illustrated by the following quotes:

Response 1: The drugs make us get stomach pains and some children get diarrhoea and vomit a lot after.

Response 2: The drugs gave me a headache, I became very dizzy and I collapsed after taking them. I went home. (Focus group discussion with girls aged 10-14 years, grades 4-6)

In one of the schools, it was reported that the head teacher tried to set a good example by swallowing four praziquantel tablets in front of the children during a school parade as a way of encouraging the children to take the drugs. Shortly afterwards, however, he fell very ill and had to abandon the parade in order to take a rest in his office. The child who was narrating the story wondered:

If the drug can make our headmaster sick, how about us, we the children? It is a very strong drug for sure. (School boy, focus group discussion)

A few children were aware that praziquantel is supposed to be swallowed after eating food to reduce its side-effects. However, most of the schools do not provide meals since the school feeding policy stipulates that parents should provide food for their children. Children were, therefore, reluctant to take the drug on empty stomachs. One child explained that: 
Our teachers tell us to swallow the tablets with food when there is no food at school; some children come from home without eating anything, so some children dodge to swallow them for fear of what will happen afterwards. (School child, focus group discussion)

Although the school feeding policy in Uganda recommends that school children should carry a snack from home for break and lunch this is not always the case, as explained by one of the teachers:

Our children don't eat anything while at school. During break and lunch time, they only go to play football and netball. (Key informant, teacher)

Teachers, aware of the side-effects of praziquantel, are reluctant to give the drug to the children on empty stomachs. To quote:

We know that these drugs are dangerous if taken without food. Instead of seeing our children collapse under a tree as one did, when those people from the district bring the drugs and go away, we just keep them because we don't want to see our children vomiting and collapsing in the school compound after swallowing the drugs. (Key informant, teacher)

Children also confessed that at times they deliberately absented themselves from school during MDA as a result of this fear. One of the children explained that:

When our teachers inform us that they will be distributing the drugs, we don't come to school during that time so that we find when the drugs have been taken away. (School child, focus group discussion)

A teacher in charge of health and sanitation at one primary school confirmed this and explained that they had resorted to taking the children by surprise:

Most children do not want to take the drugs because they have had bad experiences with the drugs before. When we give them prior information about MDA, they do not turn up at school. So we have changed strategy. We take them by surprise and distribute the drugs in class without giving them any prior information. All the children present in class on that day are forced to swallow the drugs. (Key informant, teacher)

One of the health assistants in Jinja municipality explained that people in the community also fear the side-effects of praziquantel and that the children hear these stories in the community. As a result, they have also developed negative attitudes towards the medicines:

Without doubt, the occurrence of side-effects attributable to praziquantel generates a lot of anxiety and the fear of treatment among community members and this contributes to the low uptake of drugs among primary school children. (Key informant, health assistant)

It is evident that as part of health education there is a need to explain to the children, and to the members of the community as a whole, why people experience side-effects and how this could be avoided.

\section{Institutional factors}

Administration of preventive drug treatment in primary schools is perceived by the MDA programme as the responsibility of school teachers. Teachers are expected to 
distribute and record the treatment in the registers. A minimum of two teachers from each school are trained and a small allowance of about 2 US\$ and a T-shirt are given to each teacher as an incentive for this work. However, the teachers interviewed did not perceive these tasks as part of their routine duties. They instead perceived them as extra work for which they needed to be compensated. Nearly all teachers perceived the incentive given as inadequate. They explained that poor teacher involvement in drug distribution was partly due to this:

We are not given any facilitation. We only get a small allowance during training. Teachers are tired of this voluntary work and have dropped out of the exercise, leaving other teachers who are not trained to distribute the drugs. All we need is a small allowance for distributing the drugs; otherwise, we are being asked to do a lot without any remuneration. (Key informant, teacher)

Another concern expressed by the teachers was that the numbers of teachers trained per school to distribute treatment was insufficient and there were no extra allowances given for the additional work:

Only a few of us are trained to distribute the drugs to the whole school yet we are not given any allowance. Teachers who are not involved in the training feel they are left out of the programme and do not assist us in any way during drug distribution because they think we are paid for the work we are doing. More teachers should be trained to do this work. (Key informant, teacher)

The inadequate facilitation of teachers was also acknowledged by the programme personnel. In particular, inadequate funding to facilitate training of more teachers was reported by the District Vector Control Officer, who explained that:

The budget is limited; that is why only two or three teachers are trained per school. Otherwise, we always have enough drugs, registers, tally sheets and dose poles. The challenge is that the people to manage them are few.

This was echoed by one of the health assistants, who explained that:

During the last MDA, I had to distribute the drugs myself because the trained teachers were too few to handle some big schools. Budgetary constraints do not allow us to train more teachers. (Key informant, health assistant)

In addition to a lack of incentives and too few teachers being involved, teachers also felt that the registers they are expected to fill in were an additional burden. Most of the teachers echoed the difficulties they experienced in filling out the current treatment registers because they involve filling in many other drugs for different children at different times, as expected with the integrated Neglected Tropical Diseases (NTD) treatment registers. As a result, some teachers give out the drugs without completing the treatment registers. To quote one of the teachers:

The registers are too complex, there are a number of treatments to be recorded in the registers including ivermectin, albendazole, Zithromax and praziquantel and yet these treatments are not given at the same time. For example, we give Zithromax a week earlier before albendazole and praziquantel. So we get mixed up when one has to record different 
types of treatment for different children at different times. Some teachers end up not filling the registers. (Key informant, teacher)

It is a lot of work for one to give out treatment and at the same time record the treatment in the registers which are very detailed. You have to write the names, age, sex of the child, and at the same time, measure the child's height on the dose pole to determine the number of tablets to give. (Key informant, teacher)

The District Vector Control Officer acknowledged that treatment registration was a tedious process involving filling in the tally sheets, treatment registers and drug inventory tables. He noted:

Filling the integrated NTD treatment registers is complicated for almost everyone. Teachers have to fill the tally sheets, the treatment registers and the drug inventory tables. It is like one is doing a post doc!

He went on to suggest:

Why doesn't the Ministry of Health use tally sheets only like UNEPI does? UNEPI uses simple tally sheets and they always have good data because they are easy to fill. MDA data is very poor because majority of the teachers and the community medicine distributors do not fill the registers properly. Because of the poor documentation, one cannot use the available data to estimate coverage of MDA.

Teachers felt that their contribution to the MDA programme is not fully acknowledged, nor their time compensated for, given the increased workload that comes with their involvement in the programme. This has resulted in some of the trained teachers withdrawing from the programme. The distribution of praziquantel by untrained teachers could perhaps explain the children's lack of understanding of the rationale for preventive treatment, as well as the inadequate health education.

One head teacher suggested the use of live examples as one of the ways in which the uptake of praziquantel among school children could be improved. He explained that the recent death of a famous local artist from schistosomiasis had frightened children into taking praziquantel because they feared dying in the same way. The artist was born and bred on one of the islands in Jinja district, where schistosomiasis is highly endemic. He developed a swollen abdomen, was admitted to Jinja regional referral hospital for a few days and eventually died. According to the head teacher:

After the death of Mulekezi, all the children got scared and no longer dodge taking treatment. News of his death from bilharzia reached everywhere in Jinja town and in his village on the island and children are now scared. In the subsequent drug distribution, I am sure children will fight for the drugs. (Key informant, teacher)

Others suggested the need to improve teacher motivation by providing allowances, training more teachers to distribute and record treatment and the provision of a snack prior to MDA (to mitigate the side-effects of praziquantel). Most informants emphasized that health education for the control of schistosomiasis was insufficient and that the distribution of the drugs currently takes precedence with minimal, if any, communication about the rationale for the treatment. A teacher reported that: 
Children keep asking why we continue to give them strong tablets when they are not sick, the reason why some of them run away. They are not educated enough about bilharzia and the reasons why they should take regular treatment even when they don't feel sick. All we do is just to dish out tablets because even we ourselves are not trained to educate them. In most cases, we give them the drugs when they have not eaten anything and as a result, the drug overpowers them. (Key informant, teacher)

This suggests the need for more comprehensive health education in schools and the surrounding communities about the rationale for preventive treatment.

\section{Discussion}

This study was designed to provide an understanding of why the uptake of praziquantel treatment is low among school children in the Jinja district of Uganda. Findings from the study suggest that the low uptake of praziquantel could be explained by several interrelated influences that are discussed using the socio-ecological model. These include individual, interpersonal, institutional, community and policy factors.

At the individual level, insufficient knowledge of schistosomiasis prevention results in children's unwillingness to take the tablets. This knowledge gap corroborates well with the fact that there is insufficient health education on schistosomiasis prevention in primary schools. The impact of health education in the control of schistosomiasis has been reported elsewhere (Asaolu \& Ofoezie, 2003). It is argued that with drug treatment, the prevalence and intensity of infection will decrease when health education is concurrently implemented. The reverse is true in situations where health education is deficient (Schall \& Diniz, 2001; Lansdown et al., 2002; Poggensee et al., 2005; Yuan et al., 2005), as was the case in schools in Jinja district.

At the interpersonal level, there were shared experiences of side-effects attributable to praziquantel treatment that generated a lot of anxiety and repugnance towards the drug, not only among the children, but also among the teachers and the community as a whole. Praziquantel is widely perceived to be a strong drug that causes transient sickness and occasional fatalities (Parker et al., 2008; Parker \& Allen, 2011). While children and teachers were aware that the side-effects of praziquantel can be mitigated when the drug is taken with food, many children in the area go to school without a meal, and in some cases they have not eaten the night before due to the prevailing poverty situation. Teachers confessed that they withheld the drugs from such children because they feared they would cause serious side-effects if the children swallowed them on empty stomachs. In Swaziland, the mass treatment exercise by the national schistosomiasis control programme was suspended following hospitalization of over 800 pupils after receiving praziquantel treatment (Hodges et al., 2012). In Tanzania, treatment for schistosomiasis in schools was suspended following riots in 2008 after parents became convinced that the tablets had been sent to poison their children (Allen \& Parker, 2012). In the current study, most of the children reported having previously experienced side-effects including abdominal pain, vomiting, diarrhoea and dizziness after swallowing the drug. Similar side-effects have been reported elsewhere (Kabatereine et al., 2003; Muhumuza et al., 2013b; N'Goran et al., 2003; Parker et al., 2008; Parker \& Allen, 2011).

While it has been argued that it is cost-effective to deliver interventions through schools (Bundy \& Guyatt, 1996; Brooker et al., 2001; Magnussen et al., 2001), it is 
important to acknowledge some of the likely limitations. The introduction of the Universal Primary Education (UPE) in Uganda in 1997 increased access to primary education for a large population of children, particularly in rural areas (UBOS, 2012). However, this did not guarantee increased school attendance. For instance, the use of communities, instead of schools, to distribute praziquantel for the control of schistosomiasis in Nigeria was recommended because of the low school attendance rate in many parts of the country (Mafe et al., 2005). In primary schools, praziquantel is distributed on a grade-wise basis and children swallow the tablets under the observation of the teachers. This system makes it obligatory for children to take treatment when they are at school. To avoid taking treatment due to a fear of side-effects of the drugs, children deliberately absent themselves from school on drug distribution days, as was noted from some focus group discussions and key informant interviews. Providing food for children prior to MDA, as well as treatment to alleviate and manage the side-effects attributable to praziquantel treatment, could be considered. High coverage and better compliance to treatment for schistosomiasis among school children was achieved by the national control programme in Sierra Leone when a special feeding programme for the children and supplies such as antihistamines and paracetamol to mitigate the side-effects were provided (Hodges et al., 2012).

At the institutional level, teachers are expected to sensitize children on the importance of preventive treatment, motivate them to take the drugs and to fill out the treatment registers. The interviewed teachers complained about insufficient preparation and the extra time they had to dedicate to this activity without receiving additional support. The provision of incentives, such as facilitation allowances and in-kind gifts such as Tshirts, creates a feeling of ownership and encourages teachers in their drug distribution work (Nuwaha et al., 2005). The teachers complained that the two teachers trained per school to carry out the MDA activities were too few to effectively distribute and record treatment, especially in schools with large classes. This probably explains why little, if any, health education is provided during MDA. The complexity of the current integrated NTD treatment registers discourages teachers from recording treatment. With a limited workforce, the actual distribution of treatment takes precedence. Training more teachers per school, providing incentives such as facilitation allowances and revising the current integrated NTD treatment registers would, undoubtedly, enhance drug distribution and documentation.

At the community level, poverty also influences the uptake of praziquantel. In the study area, children go to school in the morning, without a meal and, often, without having eaten anything the night before. Many parents cannot afford to meet the cost of a daily meal while at school (GCNF, 2006). The majority of the households in the study area are within $5 \mathrm{~km}$ of the lake and children frequently visit the lake to fetch water, bathe, wash, swim and to fish (Muhumuza et al., 2009). Their risk of being infected with schistosomiasis when they come into contact with contaminated water is high, yet these are the same children whose teachers are reluctant to give them praziquantel because of the possible side-effects.

At the policy level, the Ugandan Government's policy under the universal primary education programme requires that the parents and carers of children take responsibility for feeding their children while at school (GCNF, 2006; GOU, 2008). This disregards the abject poverty in the area. Most children go without food and some take treatment on empty stomachs and experience side-effects. This, in turn, affects the uptake of treatment, 
as discussed previously. Concerted efforts by the district health team to increase awareness about schistosomiasis prevention and improve the uptake of treatment are concentrated on schools that are closest to the lake, rather than those that are further away (Muhumuza et al., 2013b).

This study shows that the low uptake of praziquantel among school children is a result of a complex interplay of factors at different levels. For uptake to improve, a multi-pronged strategy is needed, including sustained sensitization and education of the children (to increase their awareness and reduce their fears of the effects of treatment). This, in turn, will help to create a demand for treatment. In addition, it would be helpful to provide food at school as this would mitigate the side-effects attributable to praziquantel treatment. Such approaches would help to increase treatment coverage and achieve a sustained drop in the prevalence and intensity of $S$. mansoni infection among school children in Uganda.

\section{Acknowledgments}

The authors wish to thank all persons who participated in focus group discussions and key informant interviews, and are indebted to the research assistants who participated in data collection. The co-operation of the school management and the teachers who are responsible for drug distribution is acknowledged. The authors are also grateful to the Danish Ministry of Foreign Affairs for funding the study.

\section{References}

Allen, T. \& Parker, M. (2012) Will increased funding for neglected tropical diseases really make poverty history? Lancet 379(9821), 1097-1098.

Asaolu, S. O. \& Ofoezie, I. E. (2003) The role of health education and sanitation in the control of helminth infections. Acta Tropica 86(2-3), 283-294.

Brooker, S., Marriot, H., Hall, A., Adjei, S., Allan, E., Maier, C. et al. (2001) Community perception of school-based delivery of anthelmintics in Ghana and Tanzania. Tropical Medicine and International Health 6(12), 1075-1083.

Bundy, D. A. \& Guyatt, H. L. (1996) Schools for health: focus on health, education and the school-age child. Parasitology Today 12(8) (Supplement), 1-16.

Engels, D., Chitsulo, L., Montresor, A. \& Savioli, L. (2002) The global epidemiological situation of schistosomiasis and new approaches to control and research. Acta Tropica 82(2), 139-146.

GCNF (2006) School Feeding in Uganda, 2006. Report for the Global Child Nutrition Forum. URL: http://www.gcnf.org/library/country-reports/uganda/2006-Uganda-School-Feeding.pdf (accessed 25th August 2011).

Glanz, K., Rimer, B. K. \& Viswanath, K. (2008) Health Behavior and Health Education: Theory, Research and Practice, 4 th edn. John Wiley \& Sons.

GOU (2008) The Education (Pre-Primary, Primary and Post-Primary) Act, 2008 (Act 13 Supplement). Government of Uganda.

Green, L. W., Richard, L. \& Potvin, L. (1996) Ecological foundations of health promotion. American Journal of Health Promotion 10(4), 270-281.

Hodges, M. H., Dada, N., Warmsley, A., Paye, J., Bangura, M. M., Nyorkor, E. et al. (2012) Mass drug administration significantly reduces infection of Schistosoma mansoni and hookworm in school children in the national control program in Sierra Leone. BMC Infectious Disease 12, 16. 
Kabatereine, N. B., Brooker, S., Tukahebwa, E. M., Kazibwe, F. \& Onapa, A. W (2004) Epidemiology and geography of Schistosomiaisis mansoni in Uganda: implications for planning control. Tropical Medicine and International Health 9, 372-380.

Kabatereine, N. B., Kemijumbi, J., Ouma, J. H., Sturrock, R. F., Butterworth, A. E., Madsen, H. et al. (2003) Efficacy and side effects of praziquantel treatment in a highly endemic Schistosoma mansoni focus at Lake Albert, Uganda. Transactions of the Royal Society of Tropical Medicine and Hygiene 97(5), 599-603.

Kabatereine, N. B., Tukahebwa, E., Kazibwe, F., Namwangye, H., Zaramba, S., Brooker, S. et al. (2006) Progress towards countrywide control of schistosomiasis and soil-transmitted helminthiasis in Uganda. Transactions of the Royal Society of Tropical Medicine and Hygiene 100(3), 208-215.

Krueger, R. A. (1998) Focus Groups. A Practical Guide for Applied Research. Sage Publications.

Lansdown, R., Ledward, A., Hall, A., Issae, W., Yona, E., Matulu, J. et al. (2002) Schistosomiasis, helminth infection and health education in Tanzania: achieving behaviour change in primary schools. Health Education Research 17(4), 425-433.

McLeroy, K. R., Bibeau, D., Steckler, A. \& Glanz, K. (1988) An ecological perspective on health promotion programs. Health Education Quarterly 15(4), 351-377.

Mafe, M. A., Appelt, B., Adewale, B., Idowu, E. T., Akinwale, O. P., Adeneye, A. K. et al. (2005) Effectiveness of different approaches to mass delivery of praziquantel among school-aged children in rural communities in Nigeria. Acta Tropica 93(2), 181-190.

Magnussen, P., Ndawi, B., Sheshe, A. K., Byskov, J., Mbwana, K. \& Christensen, N. O. (2001) The impact of a school health programme on the prevalence and morbidity of urinary schistosomiasis in Mwera Division, Pangani District, Tanzania. Transactions of the Royal Society of Tropical Medicine and Hygiene 95(1), 58-64.

Miguel, E. \& Kremer, M. (2002) Why Don't People Take their Medicine? Experimental Evidence from Kenya. URL: http://www.researcgate.net/publication/228602508

MOH (2010/2011) Annual Health Sector Performance Report. Government of Uganda, Kampala.

Muhumuza, S., Katahoire, A., Nuwaha, F. \& Olsen, A. (2013a) Increasing teacher motivation and supervision is an important but not sufficient strategy for improving praziquantel uptake in Schistosoma mansoni control programs: serial cross sectional surveys in Uganda. BMC Infectious Disease 13, 590.

Muhumuza, S., Kitimbo, G., Oryema-Lalobo, M. \& Nuwaha, F. (2009) Association between socioeconomic status and schistosomiasis infection in Jinja District, Uganda. Tropical Medicine and International Health 14(6), 612-619.

Muhumuza, S., Olsen, A., Katahoire, A. \& Nuwaha, F. (2013b) Uptake of preventive treatment for intestinal schistosomiasis among school children in Jinja District, Uganda: a cross sectional study. PLoS One 8(5), e63438.

N'Goran, E. K., Gnaka, H. N., Tanner, M. \& Utzinger, J. (2003) Efficacy and side-effects of two praziquantel treatments against Schistosoma haematobium infection, among schoolchildren from Cote d'Ivoire. Annals of Tropical Medicine and Parasitology 97(1), 37-51.

Nuwaha, F., Okware, J. \& Ndyomugyenyi, R. (2005) Predictors of compliance with communitydirected ivermectin treatment in Uganda: quantitative results. Tropical Medicine and International Health 10(7), 659-667.

Painter, J. E., Borba, C. P., Hynes, M., Mays, D. \& Glanz, K. (2008) The use of theory in health behavior research from 2000 to 2005: a systematic review. Annals of Behavioral Medicine 35(3), 358-362.

Parker, M. \& Allen, T. (2011) Does mass drug administration for the integrated treatment of neglected tropical diseases really work? Assessing evidence for the control of schistosomiasis and soil-transmitted helminths in Uganda. Health Research Policy and Systems 9, 3. 
Parker, M., Allen, T. \& Hastings, J. (2008) Resisting control of neglected tropical diseases: dilemmas in the mass treatment of schistosomiasis and soil-transmitted helminths in northwest Uganda. Journal of Biosocial Science 40(2), 161-181.

Parker, M., Allen, T., Person, G., Peach, N., Flynn, R. \& Rees, N. (2012) Border parasites: schistosomiasis control among Uganda's fisherfolk. Journal of Eastern African Studies 6, 98-123.

Poggensee, G., Krantz, I., Nordin, P., Mtweve, S., Ahlberg, B., Mosha, G. \& Freudenthal, S. (2005) A six-year follow-up of schoolchildren for urinary and intestinal schistosomiasis and soil-transmitted helminthiasis in Northern Tanzania. Acta Tropica 93(2), 131-140.

Richard, L., Potvin, L., Kishchuk, N., Prlic, H. \& Green, L. W. (1996) Assessment of the integration of the ecological approach in health promotion programs. American Journal of Health Promotion 10(4), 318-328.

Schall, V. \& Diniz, M. C. P. (2001) Information and education in schistosomiasis control: an analysis of the situation in the state of Minas Gerais, Brazil. Memórias do Instituto Oswaldo Cruz 96, 35-43.

Stokols, D. (1992) Establishing and maintaining healthy environments. Toward a social ecology of health promotion. American Psychology 47(1), 6-22.

Stokols, D. (1996) Translating social ecological theory into guidelines for community health promotion. American Journal of Health Promotion 10(4), 282-298.

UBOS (2012) Statistical Abstract. Uganda Bureau of Statistics. URL: www.ubos.org/ .../2012StatisticalAbstract.pdf?

WHO (2002) Prevention and Control of Schistosomiasis and Soil-Transmitted Helminthiasis. WHO Expert Committee Report, WHO Technical Report Service, Geneva.

WHO (2006) Preventive Chemotherapy in Human helminthiasis. Coordinated Use of Antheliminthic Drugs in Control Interventions: A Manual for Health Professionals and Programme Managers. WHO, Geneva.

Yuan, L. P., Manderson, L., Ren, M. Y., Li, G. P., Yu, D. B. \& Fang, J. C. (2005) School-based interventions to enhance knowledge and improve case management of schistosomiasis: a case study from Hunan, China. Acta Tropica 96(2), 248-254. 